\title{
Çalışan Türk Kadınlarında Premenstruel Sendrom ve Premenstruel Distrofik Bozukluk Prevalansı ve İş Performansına Etkisi
}

The Prevalence and Impact of Premenstrual Syndrome and Premenstrual Dysphoric Disorder on Work Performance in Turkish Employee Women

\section{Elif MEȘECI 1}

1. Acıbadem Kozyatağı Hastanesi, Kadın Hastalıkları ve Doğum Kliniği, İstanbul

\section{$\ddot{O Z Z E T}$}

Amaç: Çalı̧̧an Türk kadinlarında premenstruel sendrom (PMS) ve premenstruel distrofik bozukluğun $(P M D B)$ prevalansl ve iş performansı üzerindeki olumsuz etkisini belirlemektir.

Gereç ve Yöntemler: Bu çapraz kesitsel çalışmada, Acıbadem

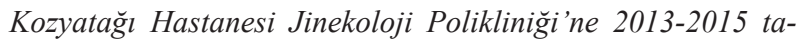
rihleri arasında başvuran, PMS/PMDB tanısı alan 232 çalışan kadına premensturel semptom ve etkilerini değerlendiren bir anket uygulanmıştır.

Bulgular: Herbir premensturel semptomun siklı̆g yüksek idi. Orta-ăgır PMS ve PMDB prevalanst sirasiyla $8.6 \%$ ve $2.9 \%$ idi. Çalışan kadınların \%44.3' ü iş performansinın etkilenmesinden şikayetçi idi. 'Yönetici konumunda çalışmak' (OO8.63,95\% GA:1.22-120.0), 'konsantrasyon güçlü̆̆̈̈' (OO3.15,95\% GA:1.0510.6), 'bitkinlik-enerji yokluğu'(OO5.92,95\% GA: 1.32-34.5) çalışma performansını olumsuz yönde arttıran risk faktörleri idi.

Sonuç: Bu çalışma premensturel semptomların sadece günlük aktiviteleri değil aynı zamanda iş performansını da çalışan kadınlarda olumsuz yönde etkilediğini göstermiştir.

Anahtar Kelimeler: PMS; PMDD; çalışan kadınlar; iş performanst

\section{ABSTRACT}

Objective: To determine the prevalence and impact of premenstrual syndrome (PMS) and premenstrual dysphoric disorder (PMDD) in Turkish employee women, with a focus on their disruption of work performance.

Material and Methods: In this cross-sectional study, Premenstrual Symptoms Questionnaire (PSQ) results of the 232 working women who applied to Acıbadem Kozyatagl Hospital Gynecology Clinic between 2013-2015 with the diagnosis of PMS/ PMDD were analyzed.

Results: The prevalence of each premenstrual symptom was high. The prevalence of moderate to severe PMS and PMDD was $8.6 \%$ and $2.9 \%$, respectively. The $44.3 \%$ of working women was found to suffer from reduced work performance. 'Working as a director' (OR8.63,95\%CI:1.22-120.0), 'difficulty concentrating' (OR3.15,95\%CI:1.05-10.6), and 'fatigue or lack of energy'(OR5.92,95\%CI:1.32-34.5) increased the risk of poor work performance.

Conclusion: This study showed that premenstrual symptoms affect not only the daily activities but also the work performance of employee women.

Keywords: PMS; PMDD; working women; work performance 


\section{GíRİs}

Premensturel sendrom (PMS) mensturel siklusun luteal fazına özgü, siklik olarak tekrarlayan ve mensturasyondan kısa bir süre sonra kaybolan duygu durum, davranış ve çeşitli fiziksel belirtilerden oluşan semptomlar topluluğudur [1, 2]. Epidemiyolojik çalışmalar kadınların yaklaşık \%75 - \% 80'inde premensturel semptomların görüldüğünü, $\% 3-8$ 'inin PMS'nin en ağır formu olan premensturel distrofik bozukluk (PMDB) tanısını aldığını göstermektedir [3-6]. PMS/PMDB etiyolojisi tam olarak bilinmemekle birlikte siklik overiyan aktivite, estradiol ve progesteronun serotonin, gamma-aminobutirik asid (GABA) gibi nörotransmitterleri etkilemesi en olası hipotezlerdir [7].

PMS/PMDB'li kadınlar luteal fazda olumsuz duygu durum değişimleri yaşamalarının yanı sira konsantrasyon, hafiza, motor koordinasyon gibi kognitif yeteneklerinde de ciddi kayıplar yaşamaktadır ve bu dönemde üretkenlikleri, yaşam kaliteleri olumsuz yönde etiklenmektedir [8, 9]. Çalışmalar PMS/PMDB'li kadınların kendilerini toplumdan soyutlama oranının bu dönemde yüksek olduğunu; çalışma performansı, okul-ev aktiviteleri, aile ilişkileri ve sosyal aktivitelerin premensturel fazda önemli ölçüde bozulduğunu göstermektedir $[10,11]$. Bu durum, sadece bireysel olarak kadınları değil aynı zamanda aile ve iş hayatını da etkilediği için sosyal bir sorun olarak tüm toplumu ve hatta ekonomiyi etkilemektedir.

Premensturel fazda kadınların yaşam kalitesinin azaldığı ile ilgili pek çok çalışma olmasına rağmen $[12,13]$ özellikle çalışan Türk kadınlarında iş performansının nasıl değiştiği konusunda bilgimiz kısıtlıdır. Biz bu çalışmamızda PMS/PMDB'nin çalıșan Türk kadınlardaki prevalansını ve iş performansı üzerindeki etkisini araştırmayı amaçladık.

\section{GEREÇ ve YÖNTEM}

$\mathrm{Bu}$ çapraz kesitsel çalışma, Acıbadem Üniversitesi Tıp Fakültesi Etik Kurul onayı ile Helsinki kriterlerine uygun olarak 2013-2015 tarihleri arasında Acıbadem Kozyatağ si'nde yapıldı. Jinekoloji polikliniğinde DSMIV-TR kriterlerine göre PMS/PMDB tanısı alan ve çalışmaya katılmayı kabul eden 232 Türk kadını araştırmaya dahil edildi [5]. Çalışma örneklemi 25-45 yaş arası; düzenli mensturel siklusları olan; oral kontraseptif, anti depresan, vitamin ya da bitkisel ilaç gibi herhangi bir tedavi kullanmayan iş kadınlarından oluşturuldu. Düzensiz mensturel siklusu olan, emziren, sis- temik hastalığı olan ve tanısı konulmuş psikiyatrik bozukluğu olan hastalar çalışma dışı bırakildi.

Premensturel semptomları değerlendirmek için Premensturel Semptomlar Anketi'ni (PSA) kullandik [14]. PSA, DSM-IV-TR kriterlerini semptomların şiddeti ölçüsünde değerlendirmeyi sağlayan bir ölçektir. $\mathrm{Bu}$ ankette son 3 ay içerisinde, mensten 1 hafta önce başlayan, mens bitimi sonrasındaki birkaç günde kaybolan semptomların varlığı sorgulanır. Depresif ruh hali; kaygı-gerginlik; ağlamak; kızgınlık-alınganlık; iş, ev ve sosyal aktivitelere ilginin azalmasi; konsantrasyon güçlügü̈; yorgunluk-enerji yokluğu; aşırı yemek-yiyecek aşermesi; uykusuzluk-aşırı uyumak; kendini yenik hissetmek; meme hassasiyeti, şişkinlik, baş ağrısı, kas-eklem ağrısı, kilo artışı gibi fiziksel belirtiler ankette sorgulanan semptomlardır. Ayrica bu semptomların 'iş verimi-üretkenlik, ev sorumlulukları, sosyal yaşam aktiviteleri, iş arkadaşları-aile ilişkileri' ile etkileşimi sorgulanır ve 'yok', 'hafif', 'orta', 'şiddetli' olmak üzere derecelendirilir. Çalışmamızda PMS'li çalışan kadınları 'PMDB', 'orta-şiddetli PMS', 'yok/ hafif PMS' olarak üç gruba ayırdık. Ankete ek olarak bu semptomların 'işteki performans ve rekabeti' nasıl etkilediğini sorguladık. Bu soruyu da anketteki gibi 'yok', 'hafif', 'orta', 'şiddetli' olmak üzere derecelendirdik. Ayrıca hastaların yönetici konumunda çalışıp çalışmadığını, çay-kahve içme alışkanlıklarını, tuzlu ya da tatlı yiyeceklere aşermelerini ve dismenorenin şiddetini sorguladik. Anketler eğitimli tek bir hemşire tarafindan hastayla yüz yüze görüşme yapilarak tamamlandi. Istatisiksel analizler JMP 10.0.2 (SAS, Cary,NC) kullanılarak gerçekleştirildi. Veriler ortalama \pm standard sapma olarak sunuldu ve $\mathrm{P}<0.05$ olan değerler istatistiksel olarak anlamlı kabul edildi.

\section{BULGULAR}

Toplam 212 çalışan kadın anketi tamamladi. Bunların 38'i ankette yetersiz bilgi olduğu için çalışmadan çıkarıldı. Böylece çalışmamızda yaşı 25-45 (ortalama 34.33 \pm 8.43 ) arasında olan 174 iş kadınına ait verileri analiz ettik. Kadınların \%81'i üniversite mezunu, \%15'i lise mezunu, \%2'si ortaokul-ilkokul mezunu, \%2'si okur-yazar idi. Evli olanların oran $1 \% 78$, boşanmış olanların oranı \%12, bekâr olanların oranı ise $\% 10 \mathrm{idi}$.

Çalışma örneklemimin karakteristikleri Tablo- 1'de sunulmuştur. Kadınların \%66.7'i $(\mathrm{n}=116)$ 'yönetici konumunda çalışmakta' idi, $\% 82.8$ 'i $(n=144)$ premensturel dönemde 'tatl yiyeceklere aşermekte' idi. 
Tablo 1: Çalışma örnekleminin karakteristikleri ( $N=174)$

\begin{tabular}{|c|c|c|c|}
\hline \multicolumn{4}{|l|}{ Karakteristikler } \\
\hline Çalışma şekli & \multicolumn{3}{|c|}{$\mathrm{n}(\%)$} \\
\hline Seyahat ederek çalışan & $44(25.3)$ & & \\
\hline Home ofis çalışan & $12(6.9)$ & & \\
\hline İşçi konumunda çalışan & $20(11.5)$ & & \\
\hline Masabaşı çalışan & $59(33.9)$ & & \\
\hline Vardiyalı işte çalışan & $20(11.5)$ & & \\
\hline Diğer & 19(10.9) & & \\
\hline Sıradan çalışan & $81(46.6)$ & & \\
\hline Yönetici konumunda çalışan & $116(66.7)$ & & \\
\hline Tuzlu yiyeceğe aşermek & $96(55.2)$ & & \\
\hline Tatlı yiyeceğe aşermek & $144(82.8)$ & & \\
\hline Çay-kahve tercihi & $69(39.7)$ & & \\
\hline \multirow[t]{2}{*}{ Dismenore } & Yok & Hafif & Orta Şiddetli \\
\hline & $22(12.6)$ & $62(35.6)$ & $64(36.8) 26(14.9)$ \\
\hline
\end{tabular}

Tablo 2: Premensturel semptomların prevalansı; iş, günlük aktivite ve ilişkiler ile etkileşiminin ölçütlenmesi (N=174).

\begin{tabular}{|c|c|c|c|c|}
\hline Semptomlar & Yok & Hafif & Orta & Şiddetli \\
\hline \multicolumn{5}{|l|}{ Premensturel semptomlar } \\
\hline Depresif ruh hali, n(\%) & $81(46.6)$ & $51(29.3)$ & $37(21.3)$ & $5(2.9)$ \\
\hline Kaygı-gerginlik, n(\%) & $35(20.1)$ & $64(36.8)$ & $60(34.5)$ & $15(8.6)$ \\
\hline Ağlamak, n(\%) & $90(51.7)$ & $45(25.9)$ & $28(16.1)$ & $11(6.3)$ \\
\hline Kızgınlık-alınganlık, n(\%) & $46(26.4)$ & $70(40.2)$ & $44(25.3)$ & $14(8.0)$ \\
\hline İş,ev,sosyal aktivitelerine ilgi azalması,n(\%) & $91(52.3)$ & $60(34.5)$ & $18(10.3)$ & $5(2.9)$ \\
\hline Konsantrasyon güçlüğü, n(\%) & $69(39.7)$ & $70(40.2)$ & $32(18.4)$ & $3(1.7)$ \\
\hline Yorgunluk- enerji yokluğu, n(\%) & $49(28.2)$ & $75(43.1)$ & $39(22.4)$ & $11(6.3)$ \\
\hline Aşırı yemek- yiyecek aşermesi, n(\%) & $48(27.6)$ & $59(33.9)$ & $46(26.4)$ & $21(12.1)$ \\
\hline Uykusuzluk-aşırı uyumak, n(\%) & $79(45.4)$ & $52(29.9)$ & $30(17.2)$ & $13(7.5)$ \\
\hline Kendini yenik hissetmek, n(\%) & $119(68.4)$ & $36(20.7)$ & $10(5.7)$ & $9(5.2)$ \\
\hline Fiziksel semptomlar, n(\%) & $50(28.7)$ & $67(38.5)$ & $44(25.3)$ & $13(7.5)$ \\
\hline \multicolumn{5}{|l|}{ İş,günlük aktivite, ilişkiler ile etkileşim } \\
\hline İş verimi-üretkenlik,ev sorumluluğu, n(\%) & $90(51.7)$ & $60(34.5)$ & $22(12.6)$ & $2(1.1)$ \\
\hline Sosyal aktiviteler, n(\%) & $141(81.0)$ & $22(12.6)$ & $7(4.0)$ & $4(2.3)$ \\
\hline İş arkadaşı-aile ilişkileri, n(\%) & 124(71.3) & $40(23.0)$ & $8(4.6)$ & $2(1.1)$ \\
\hline
\end{tabular}


Tablo 3: Premensturel semptomlar nedeniyle azalmış iş performansına neden olan risk faktörlerinin multivaryant analizi.

\begin{tabular}{|c|c|}
\hline Risk Faktörleri & OO(\%95 GA) \\
\hline \multicolumn{2}{|l|}{ Genel-Yaşam Tarzı Risk Faktörleri } \\
\hline Yaş & $0.86(0.12-5.96)$ \\
\hline Yönetici konumunda çalışmak & $8.63 *(1.22-120.0)$ \\
\hline Tatlı yiyeceğe aşermek & $5.38(0.03-4325.2)$ \\
\hline Tuzlu yiyeceğe aşermek & $0.96(0.20-4.79)$ \\
\hline Çay-kahve tercihi & $1.45(0.24-9.62)$ \\
\hline Dismenore & $0.98(0.06-14.0)$ \\
\hline \multicolumn{2}{|l|}{ Premensturel Semptomlar } \\
\hline Depresif duygudurum & $1.81(0.52-6.11)$ \\
\hline Kaygı-gerginlik & $0.80(0.19-2.82)$ \\
\hline Ağlamak & $0.55(0.14-1.90)$ \\
\hline Ev, iş, sosyal aktivitelere ilgi azalması & $1.46(0.56-3.96)$ \\
\hline Konsantrasyon güçlüğü & $3.15^{*}(1.05-10.6)$ \\
\hline Yorgunluk-enerji yokluğu & $5.92 *(1.32-34.5)$ \\
\hline Aşırı yemek- yiyecek aşermesi & $0.60(0.24-1.38)$ \\
\hline Uykusuzluk-aşırı uyumak & $0.84(0.31-2.20)$ \\
\hline Kendini yenik hissetmek & $0.87(0.18-3.38)$ \\
\hline Fiziksel semptomlar & $0.53(0.18-1.37)$ \\
\hline \multicolumn{2}{|l|}{ İş, günük aktivite, ilişkilerin etkilenmesi } \\
\hline İş üretkenliği-verimlilik, ev sorumluluğu & $0.71(0.23-2.21)$ \\
\hline Sosyal aktiviteler & $1.72(0.54-5.94)$ \\
\hline Aile, iş arkadaşları ile ilişkinin etkilenmesi & $2.57(0.76-9.53)$ \\
\hline
\end{tabular}

Tablo-2 her bir premensturel semptomun prevelansını göstermektedir. Kadınların yarisindan fazlas1 'depresif ruh hali'(\%53.4), 'kayg1-gerginlik'(\%79.9), 'kızgınlık-alınganl1k'(\%73.6), 'konsantrasyon güçlüğü'(\%60.3), 'yorgunluk-enerji yokluğu'(\%71.8), 'aşırı yemek-yiyecek aşermesi'(\%72.4), 'uykusuzluk-aşırı uyumak'(\%54.6), 'fiziksel semptomlar'(\%71.3) yaşadığını ifade etti. Premensturel semptomların çalıșan kadınlarda 'iş verimi-üretkenlik, ev sorumluluklarını'\%48.3, 'sosyal yaşam aktivitelerini'\%19.0, 'iş arkadaşları-aile ilişkilerini' $\% 28.7$, 'iş performansını'\%44.3 oranında olumsuz yönde etkilediğini gözlemledik. 'Kaygı-gerginlik', 'kızgınlık-alınganlık','iş-ev-sosyal aktivitelere ilgi azalması', 'aşırı yemek- yiyecek aşermesi've 'fiziksel semptomlar'PMS'li çalışan kadınlarda en bariz olan semptomlar idi.
'PMDB' grubunda 5 iș kadını (\%2.9), 'orta-şiddetli PMS' grubunda 15 iş kadını (\%8.6), 'yok-hafif PMS' 154 iş kadını (\%88.5) mevcut idi. Çalıșan kadınlar iș performansının olumsuz etkilenmesinden $\% 44.3$ oranında şikayetçi idi. Azalmış iş performansı ile ilişkili faktörlerin multivaryant analiz sonuçları Tablo- 3'de gösterilmiştir. 'Yönetici konumunda çalı̧̧mak', 'konsantrasyon güçlüğü', 'yorgunluk- enerji yokluğu' iş gücünü olumsuz yönde etkileyen başlıca risk faktörleri idi.

\section{TARTIȘMA}

Kadınlarda ovariyan hormonal aktivitedeki değişimler, artmış psikolojik-bilinçsel duyarlıık, premensturel dönemde artan eksternal stres faktorleri nöro-endokrin sistemin işleyişini olumsuz etkilemekte ve PMS/PMDB'i indüklemektedir [19]. Özellikle yoğun çalışma temposu olan, rekabet ortamında çalışan iş kadınları PMS/ PMDB'den en çok etkilenen populasyonu oluşturmaktadır. Günümüzde kadınların iş hayatındaki sayı ve etkinliğinin her geçen gün arttığını düşünecek olursak PMS/PMDB önemli bir toplumsal sorun haline gelmektedir. Çünkü kadınlar toplumda geleneksel anne, ev kadını, eş rollerinin yanı sıra iş kadınlığı rolünü de üstlenerek ciddi bir iş gücü katılımı sağlamakta ve sosyo-ekonomik hayatın temel taşını oluşturmaktadır.

Pekçok çalışma PMS'li kadınlarda işe gitmemek, üretkenlik azalması, iş kalitesinin düşmesi, kişisel iliş̧kiler ve sosyal aktivitelerde zorlanma gibi sorunların yaşandığını göstermektedir $[15,16]$. Ciddi PMS/PMDB'li kadınları PMS olmayan/hafif PMS'li kadınlar ile kıyaslayan Borenstein J.E.'nin çalışmasında, ciddi PMS/PMDB'li grupta sağlık sorunları nedeniyle işe gitmemek, bir sağlık kuruluşuna başvurmak-sağlık harcaması yapmak, işgücü kayb1 ve sosyal hayatın olumsuz etkilenmesi oranlarının daha yüksek olduğu gösterilmiştir [17]. PMDB'nin ekonomik maliyetini araştıran, 1194 hastayı içeren prospektif bir başka araştırmada ise prementurel fazda görülen üretkenlik azalmasının en bariz işgücü kaybı olduğu gözlenmiştir [18]. Biz araştırmamızda çalışan Türk kadınlarında premensturel semptom prevalansinın oldukça yüksek olduğunu; iş, sosyal aktivite, kişisel ilişkilerin stresle orantılı olarak olumsuz yönde etkilendiğini gözlemledik. 'Kaygı-gerginlik' [\%79.9], 'kızgınlık-alınganlık' [\%73.6], 'aşırı yemek-yiyecek aşermesi' [\%72.4] en sik görülen semptomlar idi. Kadınlar özellikle kayg1 ve yemek bozukluğunun mensturel siklus ile abartılı olarak değiştiğini ifade ettiler. Multivaryant analizi 'konsantrasyon güçlüğü', 'yorgunluk-enerji yokluğu' gibi premensturel semptomların işgücünü etkileyen en belirgin risk 
faktörleri olduğunu gösterdi. Genel ve yaşam tarzı faktörleri arasında ise 'yönetici konumunda çalışmak' en önemli risk faktörü idi. Yönetici konumunda olan kadınlar, kendilerinden daha yüksek 'iş verimi-üretkenlik' beklentisi olduğu için sıradan çalışana kıyasla daha stresli çalıştıklarını ve bunun iş performansını olumsuz etkilediğini ifade ettiler. Bu nedenle özellikle 'yönetici konumunda çalışan kadınlar 'PMS/PMDB'den işgücü kaybı açısından en çok etkilenen grubu oluşturmakta idi. Ayrıca çalışmamızda dismenore ve PMS/PMDB arasında herhangi bir ilişki saptamadık.

Çalışmamızın kısıtlı yönü, örnek kitlemiz yaș dağılımı, diğer sosyo-dermografik veriler açısından homogen bir grup olduğundan farklı gruplara ve çalışmayan kadınlara ait verilere ulaşılamadı. Böylece olası farklılıkların bilgi üzerine olan etkisi değerlendirilemedi. Ayrıca veriler kişisel cevaplamaya dayandığından subjektiftir ve çalışmayı tartışmaya açık hale getirmektedir.

Araştırmamızda saptanan veriler 1şığında, çalışan kadınların neredeyse yarısının premensturel semptomlardan olumsuz etkilendiğini düşünecek olursak kadınların işgücü katılımını arttırmak ve bu katılımın kalitesini yükseltmek, ülkemizin kalkınma çabaları bakımından şüphesiz büyük önem taşımaktadır. Bu nedenle PMS/ PMDB'nin toplumda farkındalığını arttırmak, iç gücü kaybını azaltmak ve iş performansını arttırmaya yönelik tedbirler almak başlıca hedeflerimiz olmalıdır.

\section{KA $\boldsymbol{A N} \boldsymbol{A} \boldsymbol{K} L \boldsymbol{A} R$}

1. Freeman EW. Premenstrual syndrome and premenstrual dysphoric disorder: definitions and diagnosis. Psychoneuroendocrinology $2003 ; 28(3): 25-37$.

2. Halbreich $U$. The diagnosis of premenstrual syndromes and premenstrual dysphoric disorder-clinical procedures and research perspectives. Gynecol Endocrinol 2004;19:320-34.

3. Hylan TR, Sundell K, Judge R. The impact of premenstrual symptomatology on functioning and treatment-seeking behavior: experience from the United States, United Kingdom, and France. J Womens Health Gend Based Med 1999;8:1052.

4. Johnson SR, McChesney C, Bean JA. Epidemiology of premenstrual symptoms in a nonclinical sample. I. Prevalence, natural history and help-seeking behavior. J Reprod Med 1988:33:340-6.
5. American Psychiatric Association. Diagnostic and Statistical Manual of Mental Disorders 2000. p. 771-4.

6. Yang M, Wallenstein G, Hagan M, Guo A, Chang J, Kornstein S. Burden of premenstrual dysphoric disorder on health-related quality of life. J Womens Health (Larchmt) 2008;17:113-21.

7. Panay N. Management of premenstrual syndrome. J Fam Plann Reprod Health Care 2009Jul;35(3):187-94.

8. American Psychiatric Association. Diagnostic and Statistical Manual of Mental Disorders, 4th ed. Department of Health and Human Services, Washington, DC, U.S. 1994.

9. Diener D, Greenstein FL, Turnbough PD. Cyclical variation in digit-span and visual-search performance in women differing in the severity of their premenstrual symptoms. Percept. Mot. Skills 1992;74: 67-76.

10. Borenstein J, Chiou CF, Dean B, Wong J, Wade S. Estimating direct and indirect costs of premenstrual syndrome. $J$ Occup Environ Med 2005;47:26-33.

11. Dean BB, Borenstein JE. A prospective assessment investigating the relationship between work productivity and impairment with premenstrual syndrome. J Occup Environ Med 2004;46:649-56.

12. Gonda X, Telek T, Juhász G, Lazary J, Vargha A, Bagdy G. Patterns of mood changes throughout the reproductive cycle in healthy women without premenstrual dysphoric disorders. Progress in Neuro-Psychopharmacology \& Biological Psychiatry 2008;32:1782-88.

13. Reed SC, Levin FR, Evans SM. Changes in mood, cognitive performance and appetite in the late luteal and follicular phases of the menstrual cycle in women with and without PMDD (premenstrual dysphoric disorder). Hormones and Behavior 2008:54:85-193.

14. Takeda T, Tasaka K,Sakata M, Murata Y. Prevalence of premenstrual syndrome and premenstrual dystrophic disorder. Arch Womens Ment Health 2006;9:209.

15. Borenstein J, Chiou CF, Dean B, Wong J, Wade S. Estimating directand indirect costs of premenstrual syndrome. J Occup Environ Med 2005;47:26-33.

16. Dean BB, Borenstein JE. A prospective assessment investigating therelationship between work productivity and impairment with premenstrualsyndrome. J Occup Environ Med 2004:46:649-56.

17. Borenstein J E, Dean BB, Leifke E, Korner P, Yonkers $K A$. Differences in symptom scores and health outcomes in premenstrual syndrome. Journal of Women's Health 2007; 16: 1139-44.

18. Chawla A, Swindle R, Long S, Kennedy S, Sternfeld B. Premenstrual dysphoric disorder is there an economic burden of illness. Medical Care 2002;40: 1101-12.

19. Nillni YI, Toufexis DJ, Rohan KJ. Anxiety sensitivity, the menstrual cycle, and panic disorder: A putative neuroendocrine and psychological interaction. Clin Psychol Rev. 2011Nov;31(7):1183-91. 